\title{
Effects of Intelligent Tutoring Systems (ITS) on Personalized Learning (PL)
}

\author{
Yasar Akyuz \\ Computer Sciences Program, International Black Sea University, Tbilisi, Georgia \\ Email: yakyuz2014@yahoo.com
}

How to cite this paper: Akyuz, Y. (2020). Effects of Intelligent Tutoring Systems (ITS) on Personalized Learning (PL). Creative Education, 11, 953-978.

https://doi.org/10.4236/ce.2020.116069

Received: April 20, 2020

Accepted: June 27, 2020

Published: June 30, 2020

Copyright $\odot 2020$ by author(s) and Scientific Research Publishing Inc. This work is licensed under the Creative Commons Attribution International License (CC BY 4.0).

http://creativecommons.org/licenses/by/4.0/

\begin{abstract}
With the advancements of technological solutions and the changes in human society has brought personalized learning into the limelight. A major technological solution has stream rolled personalized learning around the world in the development and advancements of Intelligent tutoring systems. The review of previous researches and in-depth analysis of several studies have proved that an intelligent tutoring system has made a positive impact on personalized learning, bringing some visible contributions in enhancing the performance of students and providing better time management. This research explores and unveils what personalized learning is all about and the role of an intelligent tutoring system in personalized learning. The work also covers how intelligent tutoring system has enhanced the performance of students, reduced cost for training institutes and educational system. The data in this research was collected through several means ranging from Internet research, one-on-one interviews, observations, and Educational Focus groups. Through the research methods, theoretical and empirical data were gathered. For interviews, data was effectively analyzed using content analysis techniques. The research work concludes with acknowledgment of the effects of intelligent tutoring system on personalized learning.
\end{abstract}

\section{Keywords}

Intelligent Tutoring Systems (ITS), Personalized Learning (PL), Pump Algebra Tutor (PAT), Structured Query Language (SQL), Episodic Learner Model (ELM), Adaptive Remote Tutor (ART), Automated Debugger in Learning System (ADIL), Information and Communication Technology (ICT), Whole-Course Intelligent Tutoring System (WITS), Cognitive Learning, Personalized Tutoring, Tutoring Tools, Instructional Design Process, Cognitive Task Analysis, Authoring Tools, Personal Leaning Environment 


\section{Introduction}

The basic principle of the formulation of personalized learning is the assertion that each individual is unique and learns differently. Personalized learning came about through the concept of Howard Gardner's theory on multiple types of human intelligence. Personalized learning takes into account multiple variables of learning, ranging from identification of the learning style of people, and clearly, personalized learning has a range of advantages over traditional learning practices.

Humans learn differently, and learning patterns is an essential necessity for students to develop. As a result of the technological advancement and lifestyle changes, learning patterns are drastically changing and this has brought about unprecedented ways of learning. Various factors contribute to the learning patterns of individuals such as geographical location, economic, environmental factors and so much more. People would also learn from various life experiences but lately, personalized learning is considered as the most efficient method of teaching (Andersen, 2011). This is because it takes into several all the factors responsible for the learning patters of individuals.

Personalized learning is a term used to describe the various learning experiences, instructional approaches, educational programs and systematic academic strategies aimed at meeting the leaning needs of individuals. The aim of personalized learning is to merge instructions with face-to-face learning, offer instructions that are assisted through technology, and to promote the collaboration of students in increasing their knowledge about certain topics. Personalized learning operates with a purpose to establish custom learning styles and curriculum according to the needs of every single student (Miliband, 2006).

It utilizes several methods and strategies to convey relevant information and to teach every student in a unique way. It takes into consideration things like cultural background, geographical location, disability state of the individual, gender, age, and so much more to develop an efficient learning style for people.

Personalized learning is different from traditional leaning that adopts a "one size fits all" approach. In traditional leaning methods, teachers would adopt the same method to teach all the students, which is clearly a flawed system.

Teachers would assign the same project, teach the same course outline, the same type of instruction to everyone, and there is no variation between students. Whereas in personalized learning, the objectives and approaches for instructions and the content of instructions vary according to the needs of the learner. In addition to this, learning activities are designed in a way that they facilitate the student, and the content is meaningful and developed according to the capacity of the student. A big driver of personalized leaning is the development of an advanced intelligent tutoring system, and it has played a major role in the educational sector. Intelligent Tutoring systems (ITS) use advanced algorithms to provide customized learning techniques for various students according to their needs and capacity. ITS are ICT based systems that are developed and run on the 
assumption that customized learning is more effective than classroom type group leaning approaches.

The purpose of this research is to evaluate the effectiveness of ITS and how it has facilitated Personalized Learning. The scope of this research covers ITS impact, the architecture, future role, methodology, characteristics of ITS, importance of ITS, machine learning, SQL and the impact of ITS on personalized learning.

\section{Significance of the Study}

The study of Intelligent Tutoring system for personalized learning can be a present and future reference for educational institutes and parents on the benefits of ITS and how it supports personalized learning. The research goal is designed to help everyone involved in learning become aware of this learning technology and how it impacts education.

There are lots of educational institute that do not know about the relevance of Intelligent Tutorial systems and how it aids personalized learning. The aim of this study is to give an in-depth report on how ITS supports personalized learning, the advantages, disadvantages, types of ITS and the different strategies it adopts. The study would contribute to educational systems and help them make a decision on the deployment of ITS for personalized learning. The study would also enlighten parents and tutors on basic student regulations with regards to the use of Technological learning tools.

\section{Research Result}

The goal of this research is to determine how Intelligent Tutoring system aids personalized learning and throughout the research several finding were made.

The use of intelligent tutorial systems for personalized learning has been on a steady rise lately due to the dynamism, flexibility and personalization it offers. This benefit has led to the massive adoption of the technology in educational institutes and other industrial sectors. From the research it was obtained that ITS offers a range of benefits and greatly supports personalized learning. Some of the benefits if offers for personalized learning include

- Keep learners engaged for longer,

- Enables students to learn at their pace,

- Ensures that personalized learning is more interactive,

- User assistance,

- Enables students potentials to be better explored,

- Ensures that students learn at any time, and even on the go,

- Improve ICT skills,

- Ensures unbiased Judgment,

- Increased motivation,

- Better time management,

- Save cost at the long run, 
- Save training materials for future use,

- Connect people to expert analysis.

The result of this report also ascertained that $90 \%$ of students and tutors prefers personalized learning with the aid of ITS. Additionally, it was obtained that $27 \%$ of student improved drastically through the use ITS for personalized learning. When students are giving directions and education in a personalized manner they learn faster and improve significantly. It further deploys the use of infographics to convey messages in a unique way which is more memorable than traditional note system. Due to its many benefits industrial sectors are increasingly using ITS to carry out personalized training such as Onboading for staffs.

Despites the well documented benefits of Intelligent Tutoring systems for personalized learning there are also disadvantages to it. The result illustrates the following disadvantages of Intelligent Tutoring Systems for personalized learning

Social isolation: Through the extensive use of technological solutions learners would be increasingly isolated from their friends and teachers. Humans are social beings and physically interaction with people goes a long way in the human development.

Lack of communication skills: Every day interaction with people improves the human communication skills but the use of Technology for learning can greatly inhibit people from communicating with one another.

Exposure to Harmful contents: Through the constant use of technological solutions for learning People are exposed to harmful contents such as pornography and violence.

Body language: ITS system cannot determine the body language of a learning which is an obvious flaw. In traditional system of learning a teacher can read meaning into the body language of the student to determine what next to do.

Cost of implementation: The cost of implementation can be discomforting for smaller institutes and this does not encourage fairness in learning across all educational sectors. Furthermore, some Institutes do not have the necessary ICT structure to deploy ITS.

\section{Methodology}

This section talks about the research methodology of the research work. It covers the research methods, research strategy, the approach, methods of data collection, how data was analyzed, and the research limitation. Furthermore, the research strategies are outlined in details.

The purpose of the research is to find the impact of ITS on personalized leaning and several strategies were adopted for information gathering.

Research Strategy: The research carried out with respect to this work is not new but an applied strategy. A number of previous research works carried out on ITS and personalized learning was analyzed. Training and educational institutes that deployed ITS for Personalized training were analyzed, Online personalized training platforms were also analyzed to gather the necessary information. 
One on one interviews were carried out, questionnaires were used, surveys, Educational Focus groups, documents and records were also explored.

Research Method: In order to satisfy the goals and objectives of this work a qualitative research was carried out. Qualitative research accounts for small samples to be evaluated at a time, it also ensured that the outcome is measurable and quantifiable. Qualitative research also offers a holistic analysis and description of the research subject without limiting the scope. And lastly qualitative research method offers better analysis and the reason it was used instead of quantitative research methods.

\subsection{Data Collection Methods and Tools}

To satisfy the purpose of this research in-depth interview was carried out. They were mostly one on one through the internet and physical means, and they were mostly unstructured.

The aim was to perfectly understand the feelings, emotions, opinions of the participants as it relates to personal learning and Intelligent Tutoring systems. Personal interviews come with a range of advantages ranging direct contact between interviewees and interviewer thus eliminating non response rates. It also offers great flexibility in terms of discussion flows which is necessary for elaborate information gathering. During interviews respondents were giving ample time to explain their views and opinion on the subjects. It should be noted that the conversation flowed pleasantly and smoothly in most of the interview session.

Extensive research was also carried out on previous works, on the internet, and educational Focus groups. For the data collection tools semi structured questionnaires were used, online survey tools such as Survey monkey and Google forms were also used to gather information

Ethical research considerations: The research was subject to a lot of ethical considerations. All participants were fully informed through writing of the essence of the interview and they also reported their acceptance through writing. Sample members were encouraged to sign another document known as the withdrawal and Debriefing document. The aim of the ethical research considerations is to ensure that participants understand the nature of the research and also willingly accept to participate. Furthermore, it also allows participants to willingly withdraw from the interview whenever they want.

\subsection{Data Analysis}

In this study, the data was collected from different articles, interviews, research papers for analysis on the impact of Intelligent Tutoring systems on personalized learning. Different authors have given different opinions on the implementation of an intelligent tutoring system in personalized learning. Most researchers, institutions, students and trainers favored the implementation of ITS however a few others raised some objection against ITS on personalized learning. They 
claim that excessive use of technology and the internet can generate harmful results for the students. A particular researcher talked about the how children can be exposed to harmful materials such as pornography on the internet.

\section{Discussion}

It has been ascertained from the research that personalized learning is more effective than traditional learning methods. The world has drastically changed and education systems have to change as well. Although some institutions like Harvard have adopted Personalized learning system however, the majority of the educational institutes still adopt traditional method of learning.

Years ago a one size fits all approach was effectively used for training but such method are going obsolete. What the present educational system need is a leaning approach that deploys technological solutions to pace instruction tailored for students needs according to their interest, capacity and ability. Personalized leaning offers a range of advantages which includes.

Higher engagement: Rather than a passive way of teaching institutions would be able to personalize the learning environments for better engagements. Personalized learning ensures that students can better work with teachers. Students can effectively work with teachers to set and meet learning goals; have a face to face and one on one interaction with the teacher through technology. Intelligent Tutoring systems are the basic drivers of personalized learning in the $21^{\text {st }}$ century. ITS enable students to independently seek resources beyond what can be offered in traditional learning system. In the UK, it is estimated from the research that about $15 \%$ of grade 6 - 12 students have informally tutored themselves through the internet, (Statistica, 2020). They have either helped answer the question of another student or found an expert to help answer their questions online. It is also estimated that about $80 \%$ of adult would go to the internet to seek for answer should they have a question or an area of confusion, (Statisti$\mathrm{ca}, 2020$ ). Furthermore organizations have started using intelligent tutoring systems to personalize training for their staffs. This has freed up a whole lot of resources, ensured better understanding of the processes and enhanced productivity.

YouTube enterprise, Udemy, plural insight, Teachable, Educadium all offers a personalized learning environment through ITS. Today the biggest elerning platforms have millions of active users signed up, and it is estimated that by 2022 Elerning industry would grow to amount $\$ 243$ billion, (Wall Street Journal, 2019). Udemy for example offers elearning of more than 20,000 courses, teachable has more than 3 million students, 20,000 courses and 7500 instructors, (statistica, 2019).

Better time allocation and utilization: When time is properly managed productivity would be enhanced for both instructor and student. Intelligent tutoring systems uses advanced algorithms to automatically assign training and learning schedules for students and teachers which mean learning can be more effective. Some of the ITS applications are also taking over some basic task of the 
primary instructor which can enable them concentrate on higher level task. Teacher are also acting as guides and instructors rather than filling the out of fashion role of a lecturer. Lately ITS system can follow up with the student to enforce assignments.

ITS have become a major component of Personalized learning in today's educational system. The fusion of intelligent tutoring systems and personalized learning fosters the seamless collaboration and also cultivates student's engagement. From this researched it was ascertained that there is a massive $27 \%$ interest jump for students and teachers when ITS is used in collaboration with Personal learning, (Statistica, 2020).

Better understanding and Inforgraphics: ITS do not only promote greater interest for students and training but also ensures better understanding. One of the components ITS adopt to ensure better understanding for learners is Inforgraphics. In a personalized learning environment inforgraphics are used to convey messages in a powerful and effective way. Inforgraphics are a clear, artistic and concise way of presenting information in a unique way. In the fast paced word and the broadening educational sector student's attention span is drastically reducing. Unfathomable amount of information is been passed to the learners and comprehension is proving to be abortive. It is becoming difficult for learners to navigate through lengthy notes and training materials. However ITS offer infographics systems which allows learners to quickly assimilate the information. They are simple, universal and original.

\section{Effectiveness of ITS on personalized training}

In time past people also realized the benefits of personalized learning and this is one of the reason why a few parents home trained their kids. It gave them opportunity to be trained in their pace, helped convey message better and allowed the potentials of the student to be explored. Lately the buzz of personalized training has greatly skyrocketed due to the advancement of technology and the incorporation of intelligent training systems to personalized training. ITS have ensured that students can be trained from any geographical location. And today a lot of institutions are effectively utilizing it.

In today's IT world artificial intelligence is used to program ITS and four techniques are used. The knowledge base which contains the domain knowledge, the student's model which simulates, analyzes and determines how best individual student would be trained. The pedagogical module contains the instructional type and model for each student. The last component is the Interface which ensures the smooth communication between student and instructor, student and student or instructor to instructor.

The research on ITS and personal learning has produced a lot of insight however there are few ITS which are frequently used in conjunction with personal learning in schools. Institutions wanting to deploy ITS must carry out extensive research to understand the diversities, their regional interest points, the problems they want to solve and the students model. As a result of the challenges 
with ITS system six universities came together to develop a modern ITS through the Byzantium project and it was a general purpose ITS (Kinshuk, 1996). It provided smart tutoring Applets for various subject areas and could be accessed through the internet. Since then more sophisticated and modern ITS have been developed which would typically replicate the basic role of an instructor thereby ensuring efficiency. The result of this research clearly showed that students that used ITS system for personalized leaning had significant improvement. Educational institutes also reduced running cost and improved efficiency.

With ITS system knowledge tracing and tracking of student's progress is more efficient. Instructors are greatly using this model to analyze the weaknesses of student and help build their strengths.

The world is changing and people are now relying on technology for fulfillment of their needs. The educational sector is one that has experienced significant ways of learning in the last two decades and in other to support the educational systems a study was conducted by (Dabae, Yeol Huh, Chun, \& Charles, 2018). They studied the demand for ITS in educational organizations by teachers. The results suggested that more than half of the teachers want to use technologically equipped systems for delivery of lectures but sadly most of the organizations are not providing this facility. There is no doubt that ITS has increased the efficiency of students, (Ghali, Ayyad, Naser, \& Laban, 2018) proved in their study that more than $97 \%$ of the teachers were satisfied with the materials provided by ITS and $90 \%$ students benefit from this system and recorded significantly measurable result

However, some researchers have claimed that human tutors are more efficient than computer systems.

(Lepper \& Woolverton, 2002) claimed that human tutors can easily and more efficiently assign the tasks and access the students but this idea was rejected by Van Lehn and he proved in his study that ITS is more efficient for personalized learning. (Briggs, 2014) criticized ITS because of his perceived difficulty in evaluation its performance. (Soffar, 2019) claimed that the application of ITS is dependent on the understanding of students regarding the new systems, which is a major drawback. (Lynch, 2018) suggested that increased utilization of these systems can create technology addiction in children. But (Lynch, 2018) has favored ITS in terms of its services and suggested that ITS provide unbiased assessment and provides help in the assessment of the future performance of students without prejudice, and physical abuse.

After the analysis of the various studies concerning ITS, it has been concluded in this report and many researchers agree that ITS has made tremendous impact on personalized learning but there is a need for modification in some areas of the ITS such as making them more accessible and convenient for users.

Parents and teachers should also observe the activities of their wards while they use ITS because of the well documented negative impacts of the internet. Technology should also be used for the betterment of the human race and the 
planet.

Assumption of ITS: Intelligent tutoring system operates on the basis of two assumptions. First of all, this model assumes that knowledge is better acquired through the delivery of customized experience. It starts with a sensory data and there is no requirement for it to make an instant impact and it delivers data that can be processed/absorbed. The data can also be recalled or influenced at a certain time. Consequently, the empiricism of this approach can contain not only the instant sensory information but also processed and recalled information (Aleven, et al., 2006; Ashman \& Conway, 1997). Although, what caused this processing and recalling could possibly be the underlying sensory information that is considered as the basic foundation of learning. This is why, it is necessary to differentiate the theory of ITS from rational theories that have been adopted by some scholars like Kant, Leibniz, and Spinoza (Smith, 1918).

As far as the ITS is concerned, there is no prior knowledge and this system is designed to provide response to the empirical cognitive operations for the students (Wertheimer, 1990). Because of the empirical basis of this theory, student can be perceived as a clean slate when it comes to the areas of knowledge or understanding of certain subject (Aleven \& Ashley, 1997; Aleven, et al., 2006; Anderson \& Reiser, 1998). In addition to this, adjustments can be made in ITS for incorporation of this assumption. In this case, existing knowledge is assumed as non-existent for the student, and learning begins from the very initial stage. Although, it is possible that student has some knowledge about the subject that is being taught, but the idea of a clean slate can be easily managed by the teaching system because this idea is consistent with the basic assumptions that has played an important role in generation of the tutoring system (Anderson, et al., 1990).

The second assumption of intelligent tutoring system suggests that processing can only begin once the sense datum has been acquired through the experience (de Koning \& Bredeweg, 2001). The purpose of this process is to generate the meaning out of the information of sensory data the learner is facing in the beginning of the learning experience.

It is not easy to generate meaning out of the raw information and this situation gives rise to some questions at this particular stage, the first question that arises in this situation is, how the processing of data is going to be performed and how is it possible for a student to generate meaning out of the data that he is confronted with? The answer to these questions is based on the theory that we can make sense out of things with the help of our universal knowledge of objects because the universal knowledge allows us to associate things with each other. For example, we associate certain objects with certain classes, like big cars with upper class of society and cheaper products with the lower class of the society. But, this approach is not sufficient for a beginner to resolve his queries or to find relevant answers for his assumptions. Also, beginners can face daunting difficulties in associating things or attaching meaning to the objects with the help of this association. But, this problem is not irresolvable and researchers are trying to 
find appropriate solution to answer this question (Ansari \& Sykes, 2012).

As a result of the advanced requirement of ITS, some IT firms have begun to incorporate Artificial intelligence to the system in order to make them more robust.

AI enables ITS to find the solutions of different problems and to easily fulfill the needs of teaching. AI further enable ITS to carry out more robust approaches in formulating models for various individual learning needs. They help provide immediate and customized learning instructions/feedback mechanism that greatly streamlines the learning process of students. Artificial intelligence also enables ITS to incorporate new teaching methods and to personalize the content according to the requirement of every single student. ITS are intended at supporting and improving the tutoring and learning procedures in the require field while improving the learning abilities of individual learner (Dašić, Dašić, Crvenković, \& Šerifi, 2016). Scientific research of the AI began as far back as 1970 (Zhang, Ren, \& Chen, 2005), and intelligent tutoring systems are a product of these research. These systems are developed to incorporate different characteristics of various individuals in other to provide better personalization mechanism (Dašić, Dašić, Crvenković, \& Šerifi, 2016).

Traditional ITS: Traditional ITSs are focused on areas that need training and they emphasize more on those areas that will provide the most benefit for students.

This is why they adopt an up to date domain based mechanisms. They focused on well-known traditional methods of learning and they adopt systematic approaches to mitigate against them. They try to distinguish the methodologies and eliminate the problems from their area of expertise and this is why Learning institutions must implement ITS in their system to eliminate the problems associated with traditional learning approaches (Brusilovsky, Eklund, \& Schwarz, 1998).

Architecture of ITS: There are lots of discrepancies among ITS systems and each of them typically emphasizes different approaches and elements. However, an efficient ITS architecture comes with four iterative elements which are 1) Assessment needs 2) Analysis of cognitive task 3) Tutor implementation and 4) Evaluation mechanism. The assessment need has to do with the instructional design steps with respect to software systems and mostly has to do with learner analysis and the development of expert analysis systems. It is aimed at establishing learning goals and to outline general curriculum for a personalized learning. The second stage has to do with cognitive task analysis which forms a development of a valid computational model.

It also provides a way of observing interaction between the trainer and the student.

The third stage is the Initial tutor implementation and it has to do with setting up a problem solving environment for effective learning. While the $4^{\text {th }}$ stage carries out various evaluation such as formative evaluations, parametric studies and summative evaluations. 
In addition to this, an ITS should have basic communication knowledge and should allow the system to process the required information for the students. Further to the initial architecture an ITS is broken down into another four major components; They include domain model which is responsible for storing an expert domain data; student model which is responsible for storing details about the current status of the student in order to identify the new teaching methods; tutor model which is responsible for stroing the pedagogical details. Tutor model decides strategies for students as well, and the last model is user interface model which allows access to the knowledge of different domains (Nkambou, 2010, Nwana, 1990).

A traditional architecture of intelligent tutoring system is presented in Figure 1:

ITS are established on the basis of knowledge and information because they have the knowledge about domains, principles and methods that needs to be applied according to the caliber and needs of students. ITS needs to be flexible for both the pupils and the system because flexibility would ensure better usability.

Division of ITS modules: Intelligent tutoring systems are developed on the basis of four interconnected modules (Phobun \& Vicheanpanya, 2010) (Zhang, Ren, \& Chen, 2005). These modules are the student module, the expert module, tutor module, and the user interface module.

Student Module: This module utilizes the student model and it contains details of the student knowledge, patterns, attributes and behaviors. It also gathers information's such as misconceptions, information gaps etc. (Ayop, Chaellappan, \& Nazlena, 2001). The essence of gathering student's data is to identify the educational capacity of the pupil and to determine the most relevant learning technique. However ITS do not gather the entire attributes of the student because in most cases some are irrelevant. For example, gestures, voice and appearance are

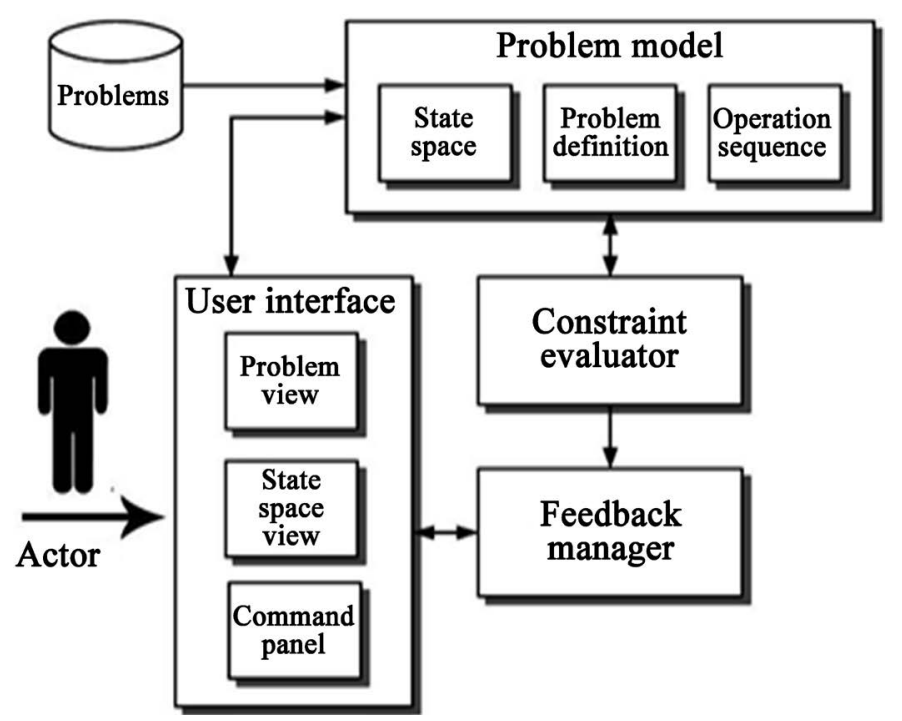

Figure 1. A traditional architecture of intelligent tutoring system. 
somewhat irrelevant (Merrill, Reiser, Ranney, \& Trafton, 1992). The gathered student information is stored in a secure data base and can be evaluated in the future. In summary, the student Module has two basic goals; to formulate a learning scheme according to the needs of the student and to assist the student in solving problems (McNally, Shute, \& Psotka, 1996; Shure \& Psotka, 1995).

Expert Module: This module is designed to accommodate expertise information that would be used in aiding the ITS to deliver expert flow (Nkambou, Frasson, \& Gauthier, 1998). All the expert knowledge is contained in this module and in most modern ITS AI is used in powering the expert module.

It has been established that an AI powered expert module is more efficient than a non AI powered module. With the expert module the tutor can easily redirect his teaching techniques according to data of the student that is stored in the student module (McNally, Shute, \& Psotka, 1996; Vassileva, 1989). It is also designed to facilitate teachers in making teaching decisions. Additionally, the Expert module is responsible for the Development of questions and their answers, thus acting like a source (McNally, Shute, \& Psotka, 1996; Frasson \& Aimeur, 1998; Self, 1999).

Tutor Module: This module is responsible for taking corrective actions. It checks to know if there is a mismatch between the student's knowledge or actions and the presumed actions of the expert. In the event of a mismatch a signal would be given to the tutor module detailing the mismatch between the expert's presumptions and the student's behavior. The Tutor module would further take the responsibility to correct the mismatch or provide remedial suggestions. In order to do this, it determines the actions a human tutor will take in similar situation. Furthermore, it contains details about the tutoring techniques that are stored in the student module and it makes its recommendation based on the attributes of the student.

In order to show the accurate results, it needs to have the control over the sequencing and choices of subject components (Frasson \& Aimeur, 1998). In addition to this, it is responsible for dealing with the queries and finding the solutions for the problems of the students. In summary the Tutor module provides the required information to achieve the goals of tutoring. Tutor Module utilizes two models in the ITS (Grandbastien, 1999); which are executive and secretive models. In the secretive model the system provides a series of question to the pupil to minimize misconceptions. Whereas in the executive model, the required information is obtained through different platforms (Salgueiro, Costa, Cataldi, Lage, \& Garcia, 2005).

User Interface Module: This module is responsible for offering the resources that provides assistance to the students in their interactions with the ITS (Salgueiro, Costa, Cataldi, Lage, \& Garcia, 2005). User interface module facilitates the interactions between students and the ITS, usually through a graphic user interface (GUI). Some of them also implement a rich stimulation of tasks that the student is trying to learn (McNally, Shute, \& Psotka, 1996). This module 
needs three types of details for the implementation of dialogues.

It requires details about the model that generated the required information for better understanding. Secondly it requires details about the area that is necessary for the generation of communication and lastly it requires details about the content which is necessary for achieving the goal of the communication (Frasson \& Aimeur, 1998; Self, 1999). User interface module is also referred as the communicating element of an ITS because it controls the interaction between system and the students or between student and the trainer. It is responsible for translating the content to make is easier and understandable for the student (Shure \& Psotka, 1995).

Inner and Outer Loop: According to VanLehn (2006), despite of the difference and lack of similarities between the ITS, these systems contain several features and perform actions that are similar in nature. ITS perform similar actions because of the involvement of two loops; they are the inner and outer loop. The inner loop monitors the progress of students within the tasks and provides relevant interventions like feedbacks, hints, reviews and assessment of information. Outerloop is responsible for deciding the tasks that needs to be performed by the students.

This decision is taken by considering the previous details and background of the student (Vanlehn, 2006).

Development in other sectors: As a result of ITS growing influence in education sector, the industrial sectors have begun to implement ITS for their operations. Most organizations have deployed a range of ITS solution to carry out on boarding and training of staffs which has greatly reduced cost for organizations. Several organizations are implementing these systems because of their assistance in providing personalized learning to its workforce. Aside from new staffs, companies would set up ITS system to provide specialized training in different areas of operation and this has resulted in improved productivity, better time management and the delivery of quality products and services. This has led to the an increasing demand for ITS and developers have introduced more robust and advanced versions of ITS for almost every industrial sector. Here are the various types of ITS.

MetaTutor: This type of ITS is established to guide students on how to solve problems, and feedback is sent to the trainer.

It is based on nine logical elements, which includes, advanced scheduling, planning, student module, multimedia interface, review/feedback, framing, assessment, authorization and management of system (Rus, Lintean, \& Azevedo, 2010). One of the major advantage of this type of ITS is Transparency. It can easily accommodate modules, and updates/modifications can be made in the model without making changes in the initial design of the system. It also allows the independence of domains, which means that the expert can edit the information stored in the files and apply this system for other domains. There is an ongoing research on this type of ITS and more development is underway (Barbhuiya, Mustafa, \& Jabin, 2011). 
A Meta Tutor Architecture is presented in Figure 2.

Pump Algebra Tutor (PAT): This model was established by the Pittsburgh Urban Math's Project. In this project students were engaged in examination of real life problems and they deployed algebraic equipments to find the solution of the problems (Koedinger, Anderson, Hadley, \& Mark, 1997). It was developed on the basis of ACT theory and the cognitive tutor model (Anderson, Corbett, Koedinger, \& Pelletier, 1995).

In this model, the tutor assesses the activities of students and gives feedback according to their performance. Most of the time, the tutor silently observes the actions of the students and do not interfere in their activities. Normally, when a student makes a mistake, this system just highlights the problematic section without giving any comments to reduce the negativity in students regarding the mathematics class. However, if the mistake in caused by lack of attention or it is marked as a human error in the system, then the system highlights the mistake and describes the problem in details (Anderson, 1996).

Andes Physics Tutoring System: This type of ITS provides help to the university level students in learning physics. It is concentrated on web based homework and provides instant feedback (VanLehn, Lynch, Schulze, \& Shapiro, 2005).

Three types of feedbacks are provided by Andes during the lecture; 1) a message would display on the screen if there is a problem caused by lack of attention instead of insufficiency of information. 2. Students can demand help by clicking on the "help" button. 3. Provision of hint for the student if they are stuck or confused in any area (Barbhuiya, Mustafa, \& Jabin, 2011).

Animal Watch: This is an ITS that is developed for students who want to learn basic computing and fraction (Beal, Arroyo, Cohen, \& Woolf, 2010). It utilizes the data of students to analyze their capabilities and selects problems that are solvable by the student. The system moves on to a new topic once the student has solved the previous problem successfully. One of the most beneficial

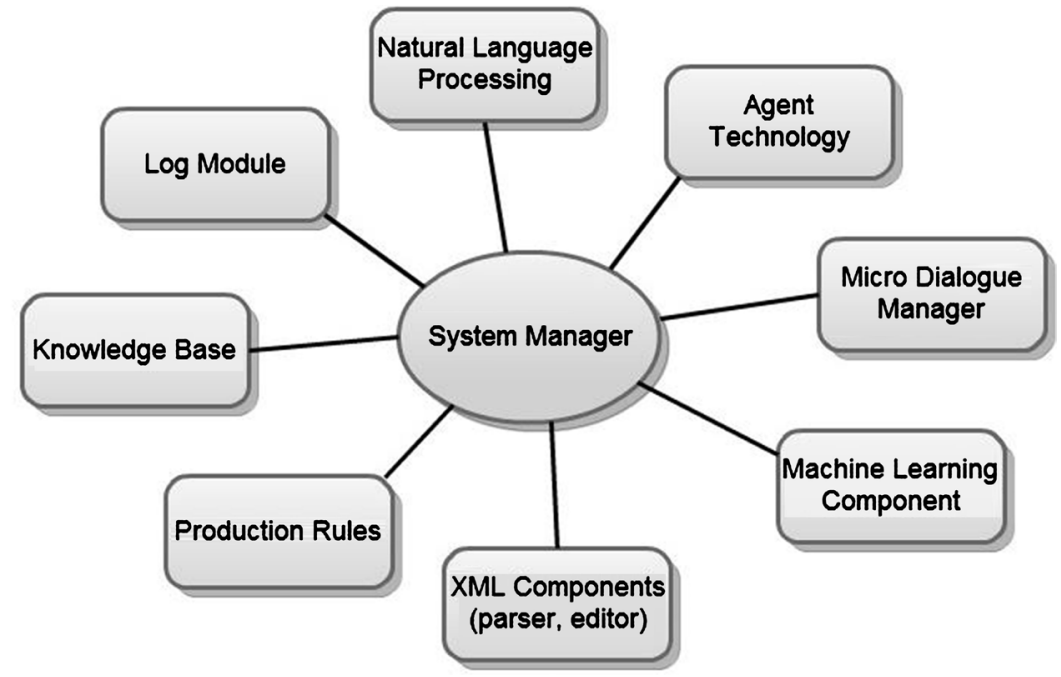

Figure 2. Metatutor Architecture (Paviotti, Rossi, \& Zarka, 2012). 
aspects of this system is the methodologies for pre and post test evaluation. This system can be used in future intelligent tutoring systems were pupil will have to be pre-test for every topic and the student module will collect the results of these test to evaluate the performance of the student. The data would then be used to decide the relevant teaching strategies (Cohen, Beal, \& Adams, 2008).

Structured Query Language Tutor (SQL-Tutor): It is a type of ITS that is used for learning SQL languages, on the basis of a given acknowledge. It adopts a CBM approach for teaching student Structured query language. It starts by selecting a question and requests the student to find the answer. Once the student has entered the answer, the pedagogical module sends it to student module, which is responsible for analyzing the response to identify mistakes and make relevant update in the student model. Then the pedagogical module takes relevant action according to the information provided by the student model. Another domain of SQL-Tutors is in the application of the SQLT-Web. It is an ITS used in giving assistance to students on the use of SQL query languages database (Mitrović, 2003).

Episodic Learner Model Adaptive Remote Tutor (ELM-ART): It is a web based ITS developed for teaching the basics of programming in list processing programming language (LISP). It incorporates ITS with the electric textbook programs and it allows the users to enhance and improve the previously acquired information (Brusilovsky, Eklund, \& Schwarz, 1998; Weber \& Brusilovsky, 2001).

It provides content in the form of adaptive textbooks to promote the learning of the programming language. ELM-ART offers sequencing of courses, customization in diagnosis of problems and adaptive navigation browsing for online support. It is established on the basis of ELM-PE (Weber \& Mollenberg, 1999) additionally, it provides support in example based programs, smart analysis of solutions, debugging services and pre-testing of systems.

Table 1 provides a comparison of the various ITSs. The evaluation of these ITSs is performed on the basis of the areas that they cover, feedback, policies,

Table 1. Specialist areas of ITSs.

\begin{tabular}{cccccc}
\hline & Covered Domains & Feedback & Usage of animated medium & Student Model & Other characteristics \\
\hline Meta Tutor & Anatomy & Verbal & Yes & Interactive Multimedia & Self-regulatory learning \\
PAT & Algebra (school level) & Instant (timely) & No & ACT Theory \\
ANDES & Physics & Instant & No (use videos for instructions) & Bayesian Network \\
Animal Watch & Mathematics & Instant & Yes & Markov Models \\
SQL Tutor & SQL Query & $\begin{array}{l}\text { Five level } \\
\text { feedback }\end{array}$ & & No & CBM (Short-term) \\
ELM-ART & LISP Programming & Instant & No & Overlay (Long-term) & Collabor ative \\
\hline
\end{tabular}


pedagogical agents and the methodology of student model (if any) being utilized.

Aside from the above mentioned ITSs, there are some other specialized ITS deployed and utilized in various fields. Here are some the major once.

Automated Debugger in Learning System (ADIL): This system is designed for automatic troubleshooting on the basis of knowledge. It targets $\mathrm{C}$ programming languages and guides the students about primary debugging techniques. It is used for rapid detection of bugs in a program and also explains the solution or how to debug. Because of the specification of ADIL, it is used for locating, detecting and explaining errors in a C program (Zin, Aljunid, Shukur, \& Nordin, 2000).

Dynamic Courseware Generation (DCG): This type of ITS is built on a shell architecture and its purpose is to apply the techniques of artificial intelligence to determine the content for instructions. It is used for dynamic generation of instructional courses and the courses are generally aimed at the development of customized instructions for each student within the goal of tutoring. It is developed by Julita Vassileva and Ralph Detersm (Vassileva; Vassileva and Deters) (Vassileva \& Deters, 1998).

Animated data structure ITS (ADIS): It is a Java based ITS established for assisting students in enhancing their understanding of data formats such as stacks, graphs, tress and lots more. ADIS can graphically present data format on screens and allow the graphical management of the created data structures. It also offers a teaching mode that gives visual guide to students about the fundamental algorithms of various data formats (Warendorf \& Tan, 1997).

Normalization Intelligent Tutor (NORMIT): This ITS is used to teach the normalization of database to students. It is a web based system and is designed to teach students queries (Mitrović, 2002).

Bayesian intelligent tutoring system (BITS): This is a web based ITS that is designed to teach programming. It provides help to students and ensures they easily browse online materials. It further provides suggestions for learning targets and generates relevant sequences for learning. The sequences make it easier for the students to prioritize their learning concepts. Furthermore, it eliminates revision and saves time (Butz, Hua, \& Maguire, 2004).

Machine learning tutor (ML-Tutor): This is a web based ITS designed to combine internet technologies with educational hypertexts.

In this system, the clients are responsible for capturing the data that is sent to the server through the web technology. After receiving the request from the client, the system executes the server component. The server uses a machine learning element to analyze the data and to share the results with the client (Smith \& Blandford, 2003).

Decision making tutor (DM-Tutor): This type of ITS is based on constraints and is used to provide situation based training through the help of real life operating data and effective plantation techniques (Amalathas, Mitrović, \& Ravan, 
2012).

Whole-Course Intelligent Tutoring System (WITS): It's an expert system ITS used to teach courses without the help of a human tutors. It is capable of generating a learning atmosphere that can motivate the students and offer instant and useful feedbacks (Callear, 1999).

JITS: The JITS is based on Java programming language and it generates a virtual programming teacher to assist the students in their initial programming courses in Java ${ }^{\mathrm{TM}}$ in colleges and Universities (Sykes \& Franek, 2004).

Multicriteria Bayesian ITS (MBITS): Bayesian is a web based ITS that is supported by the Bayesian Network.

It is user friendly, offers a very interactive training system and operates as a web based application. MBITS is aimed at assisting students by providing a better understanding of concepts with the help of multicriterian approaches to analyze the solutions and gather information with the help of same criteria (Yamna, Mellouli, \& Wuillemin, 2010).

Knowledge based entity relationship modeling intelligent tutoring (KERMIT): This type of ITS is established for entity relationship (ER) modeling. It is implemented with Microsoft visual basic programming language and assists in ER modeling. It was generated by Pramuditha Suraweera and Antonija Mitrović, at the (ICTG), in Canterbury University (Mitrović, Mayo, Suraweera, \& Martin, 2004).

Impacts of ITS on personalized Learning: Intelligent Tutoring systems have been instrumental in advancing education a great deal. Some of the advanced systems deploy Artificial intelligence and machine learning algorithms to streamline personalized learning in an interactive and efficient way. Most students perform better in a personalized environment and the system has been used to teach student in diverse educational fields.

Some of those fields include, Law, science, programining, Math's, Physics, Medicine, reading comprehension and so much more.

ITS found its way into the educational sector more than 40 years ago and it has constantly expanded into a variety of instructional functions for schools and training centers. Every Intelligent Tutoring system has the ability to capture student's performance and capabilities which cannot be achieved by human's tutors. It uses this information to control what the student is thought and how learning is carried out for individual students based on their capabilities. It often comes with an elegant interface and helps to build a streamlined students model for seamless learning. Learning from ITS is associated with higher scores regardless on the level of education.

This research found that over a range of conditions ITS offered better leaning potential for students.

It can be advised that ITS should replace large group instructor lead leaning session in every school or training institute. Figure 3 shows that the systems are on par with human tutoring, as shown by their impact/effect.

Ghali, Ayyad, Naser, \& Laban, 2018 conducted a study to analyze the impact 
of ITS on learning of English grammar. They presented this system to a group of English specialized teachers and to some university level students. The study was basically designed to get the feedback of teachers and students on the benefits, quality of system and material and the comprehensiveness of content. The result of the evaluation by teachers and students are pleasing as shown in Figure 4.

A study was conducted by Dabae, Yeol Huh, Chun, \& Charles in 2018 to analyze the demand for technological systems in educational settings.

The study included 245 teachers from 41 schools as the sample, the results suggested that only $12 \%$ teachers were provided with required technological systems from the school administration and $21 \%$ teachers stated that they were not using any of these systems for teaching activities. With the rapid advancement in the world, technology in education has become an essential component, and as far as the education is concerned, ITS are needed for better education.

Benefits of Intelligent Tutoring Systems: ITS have been adopted in other

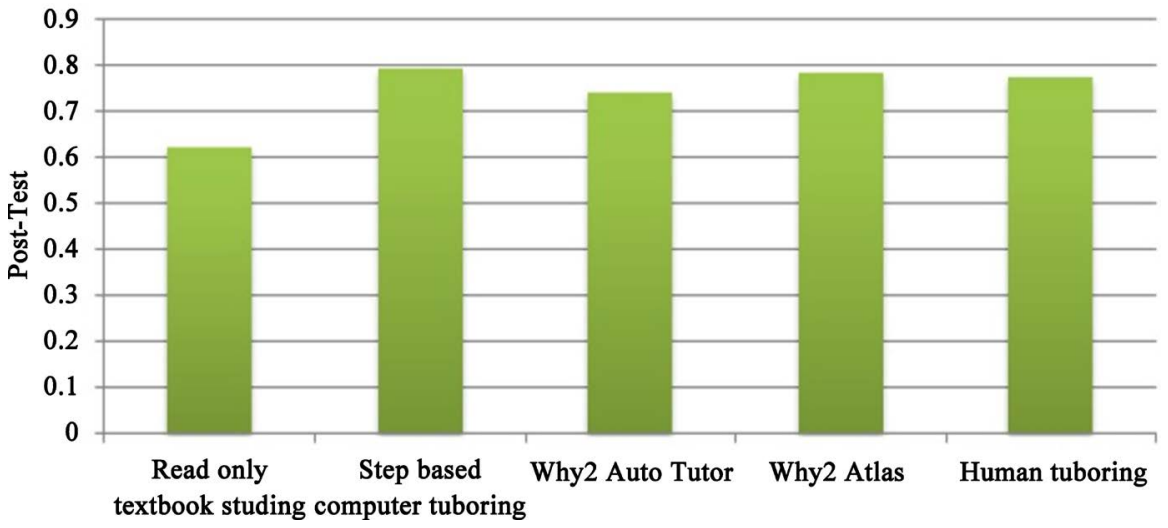

Figure 3. Different types of ITS (Alqahtani \& Ramzan, 2019).

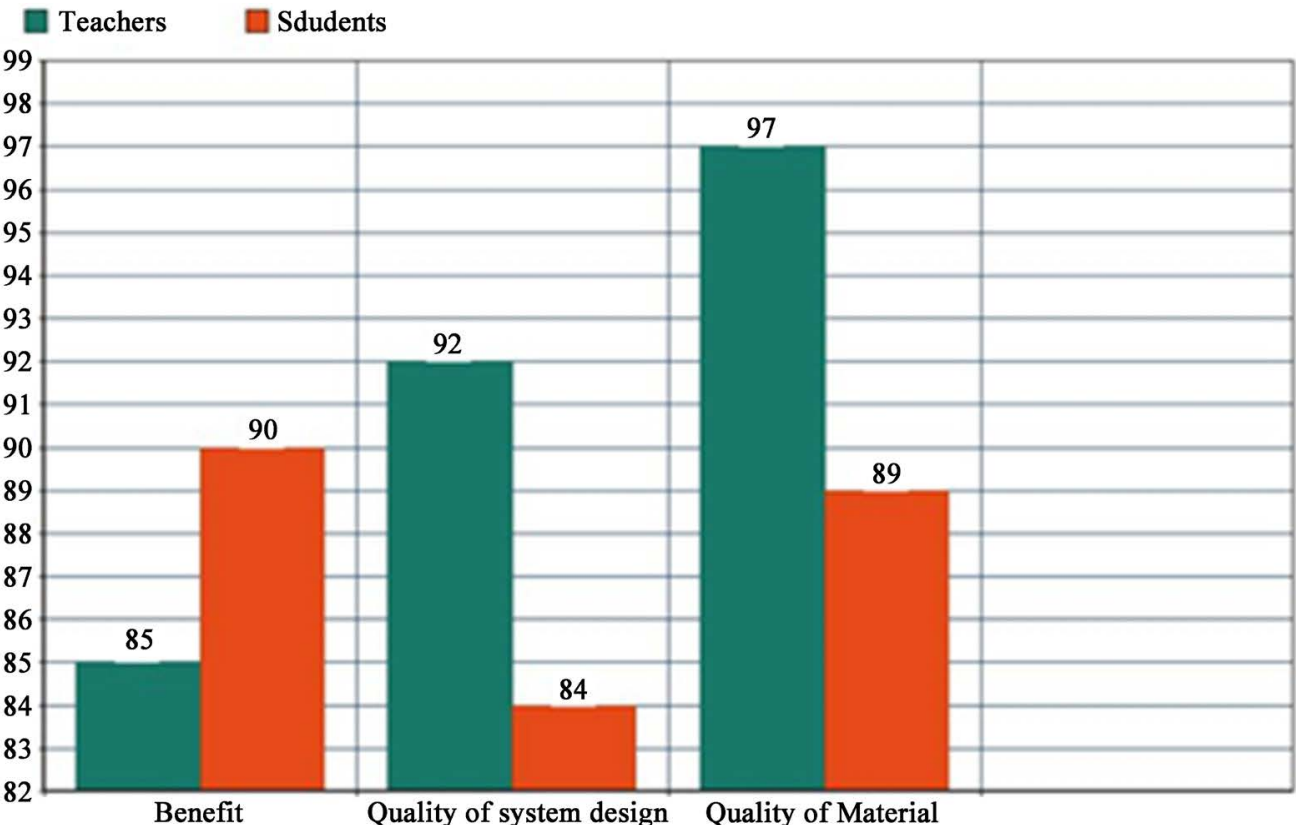

Figure 4. The results of evaluation (Ghali, Ayyad, Naser, \& Laban, 2018). 
fields other than educational institutes due to the several benefits it offers and measurable positive impact. Here are the various features.

Accessibility: Most teachers and students prefer ITS because of its availability. Students can use these systems to study at any time of the day from any location, and this has greatly accelerated personalized learning.

Feedback Mechanism: ITS provide feedback to the students and the tutor which helps in boosting performance and maximizing time. Some ITS can highlight wrong answers while solving different questions to guide the students. It can also provide instant hint when the student makes a request ...

Feedbacks allow the students to reflect on their performance and motivate them to make certain changes to improve their performance (Briggs, 2014).

Personalized Learning: ITS greatly helps in developing curriculum and training materials for individual students needs. It also enhances the capabilities and potentials of the student in a unique way. The benefits isn't meant for students alone but teachers as well have greatly benefited from ITS. It allows them deliver personalized leaning contents, manages their time, and delivers lecture in an efficient manner (Lynch, 2018).

Unbiased assessment and grading: ITS analyze and asses the students on the basis of their skills, attributes, and performance which reduces the chances of biased judgments and unfair treatment. ITS provide authentic and reliable results that are based on the individual performance of the student (Lynch, 2018).

Analyzes of future performance: ITS can assist the teachers to analyze the capability of their students and predict their future performance. It can easily analyze the data and present patterns to show the weaknesses and the strengths of students. These patterns can help the teachers to target those areas that require their attention.

It can also provide virtual tutoring in case the teacher is not able to resolve the queries of the student. Along with the other factors, ITS can also indicate alarming changes in the performance of student (Lynch, 2018).

Most of the ITS have been proven to be quite helpful in facilitating and enhancing Personalized Learning. They have provided several benefits in different areas of other than schools and training institutes.

Despite the benefits and ease of implementation ITS are facing some barriers in its deployment in educational institutes. Some of them include:

Large Number of Stakeholders: There are usually many stakeholders in an educational institute and this is a major barrier to its deployment. Most at times stakeholder would not come into agreement for its deployment due to the different thoughts and ideas about the system. The situation is more prevalent in third world countries that have to rely on developed states for the investments and introduction of new technologies. According to Bronfenbrenner (1992), families, teachers, fellows and societies directly influence the students whereas policies and cultures have an indirect affect on the skills and behavior of students. 
Keeping these factors in mind, five major barriers have been identified to be a barrier in the implementation of ITS in third world countries. These factors include: availability of ICT hardware, reliability of internet, data cost, ICT skills in the students, language and cultural barriers (Nye, 2014).

Lack of Information and Communication technology (ICT): One of the major barriers in implementation of ITS in third world countries is the lack of ICT. ICT plays an important role in enhancing the deployment and usage of technology in educational systems. Developers are trying to increase the usage of ICT in intelligent tutoring systems but the limitations of developing countries in the provision of data and ICT infrastructures are causing major difficulties in the implementation of ITS (Nye, 2014).

Reliable Internet: Without a reliable internet connection ITS cannot be effectively implemented and utilized. This is a major barrier in countries that do not have a good internet system. Although, this problem is not visible in developed countries, most of the developing countries are still struggling to overcome this issue, especially in the rural areas. Inconsistent internet can make learning difficult for the students and add to the difficulties of teachers in delivering their lectures.

It can cause delays in lectures and affect the attitude of students (Nye, 2014).

Lack of ICT skills: Studies have shown that ICT skills play an important role in the usage of IT systems. ICT skills present a wide range of understanding of applications and computer system which can help students effectively utilize ITS. Basic ICT skills include word processing, databases, search engines, spreadsheets and lots more. Lack of these skills can affect the overall learning of the student and negatively impact their adjustment (Nye, 2014).

Language barriers: For educational settings, a system may not provide the desired results if it is not available in the local language or when the students cannot interpret it effectively. It has been proved by the study that students face difficulty in using computing software because the system contains symbols or languages that are not familiar to them (Nye, 2014). Additionally, Culture-oriented aspects have also proven to be a major challenge in the adaption of technologies and new systems for learning (Casas, Imbrogno, Ochoa, \& Ogan, 2014). Cultural barriers are further divided into four categories; pedagogical process, organizational tactics, human resources and technology deployment.

Educational areas are surrounded by certain limitations in norms, values and political scenarios. These factors can negatively impact the implementation of ITS. Values and norms are among the major factors that affect the acceptability of systems. Religion affiliations sometimes can also influence people to reject some technological advancement (Ignacio, Patricia, Marcia, \& Amy, 2015).

Pedagogical processes: Current processes and the unwillingness have greatly affected the implementation of certain technologies in educational institutions. People might be so used to their legacy system that in some cases they would reject new technologies. Some, schools resist implementation of new technologies 
because they believe that these systems will distort their educational processes or sometimes their processes are not sufficient enough to effectively carry out the implementation of more technologically equipped systems.

Organizational Structure: The structure of institutes plays an important role in their acceptance and adjustment to new technologies. And sometimes authorities do not have enough resources to afford IT systems.

Human Resources: it is important to create awareness about the usage of technologies and to let everyone realize that the system is meant to boost productivity. This message ought to be conveyed by the Human resource team in a gentle approach else the system may not gain acceptance.

In developing countries, especially in rural areas, school staff is not aware about different dimensions of the technology and teachers are not aware about systems that can improve the learning of students. Students' attitude towards technology is also a barrier to some extent.

ITS is among the most effective learning technologies in the world today but barriers have affected its wide acceptance and implementation around the world. It comes with a range of advantages which include delivery of customized contents, increasing performance, better time management, and resource allocation. It has greatly helped in promoting personalized learning.

However, an intelligent tutoring system is mostly designed according to the infrastructure of developed countries. Therefore underdeveloped countries may find it a little bit difficult in the deployment and utilization of ITS for personalized learning (Nye, 2014).

Disadvantages of ITS: Most things that have an advantage also comes with disadvantages and this is also the case with ITS. Despite the numerous of ITS to personalized learning there are certain drawbacks to the technology.

Researchers have pointed out some elements in the implementation of ITS that need the attention of developers. Some of these drawbacks are mentioned below:

Difficulty in evaluation of ITS: It is difficult to assess the performance and results of an ITS without deploying it and running it over time. Even though, studies have provided several evaluation methods, educational system differs and without extensive usage institutions may not be able to tell its capacity in facilitating personalized learning.

Developers need to specify the guidelines and the working principles of individual ITS to help institution make better evaluations before purchase (Briggs, 2014).

Inability to determine subjective items: ITS makes evaluation based on the computed information of the student. That means over time IT personal must compute new sets of information about the students all over. This is because people move from various life stages and if for example a student becomes disabled the system would have to be reconfigured again. If the student becomes mentally ill the system would also be reconfigured. There are other instances 
whereby the system would need to be reconfigured which contribute to manual input.

Price Limitation: Some school administrators would hesitate in implementing ITS because of the Price. Large and wealthy institutions do not have a problem with the cost but smaller institutions have a problem with the cost.

In order to provide equal education and equal opportunities to all children, developers need to introduce systems that are less expensive but equally efficient in their application (Lynch, 2018).

Technology addiction: humans are social animals and social interaction greatly contributes to the wellbeing of a student. Continuous interaction greatly limits the interaction of students with their friends and teachers which can halt their progress. Furthermore Technology can greatly halt practical skills and physical engagements. Increased reliance on technology will affect people's ability to present themselves in the real life situations and it will only build socially awkward and technology addict adults (Lynch, 2018).

Despite the drawbacks and criticism of ITS on personalized learning, developers are working hard to overcome these issues to fulfill the needs of all students and institutions. Developers are also building functions that will enable the intelligent tutors to analyze the emotions and expressions of students to motivate them and increase their engagement in learning activities. However, developers have introduced some new fields in ITS to address the issues that are not covered in a typical intelligent tutoring system (Briggs, 2014).

\section{Conclusion}

Personal learning presents a customized educational approach where individuals are thought according to their pace, mental capacity, resource and other personal factors. Each student is thought based on how well they assimilate, what they know and their unique interest. The effective delivery of personalized learning has been greatly influenced with the incorporation of Intelligent Tutoring systems. ITS are advanced technological solutions, using artificial intelligence, process control, and machine learning to deliver instructional advice on a one on one basis. Personalized learning can never be achieved satisfactorily without the deployment of ITS. This is because ITS perfectly simulate a learning environment, act like a human teacher and provide an interface for information sharing between student and instructor, student and student and instructor to instructor.

They also offer unique and measurable way for institutions to monitor progress and enable students to learn at any time and location.

As the world is advancing, most sectors of life are drastically changing. People attention spans are getting shorter and it is evident that the traditional method of learning has become obsolete. This is because people assimilate information differently and in a class room there are several environmental, physical, economic and mental factors that greatly influence how people learn. 
Over the course of this research it was ascertained that student did $27 \%$ better when learning is personalized with ITS. It is also reported from the research that $90 \%$ of staffs and students prefer the personalized training method. This research is important because it illustrates how personalized learning through ITS can rapidly improve productivity and reduce cost for training institutions and pupils. The research is also important as it explicitly outlines the advantages of Intelligent Tutoring systems, and the drawback in implementing the educational technology system.

Intelligent Tutoring Systems for personalized learning definitely have its drawbacks but the future scope of these solutions is exciting and would mitigate against some of the drawbacks it currently has. One of the drawbacks with ITS for personalized learning is in the periodic capture of pupils learning requirements but developers are actively working to add new machine learning models to eliminate this drawback. Machine learning would enable ITS to be able understand the feelings of the student, their life stages and their thinking patterns in order to provide a tailored learning solution.

\section{Conflicts of Interest}

The author declares no conflicts of interest regarding the publication of this paper.

\section{References}

Alqahtani, F., \& Ramzan, N. (2019). Comparison and Efficacy of Synergistic Intelligent Tutoring Systems with Human Physiological Response. Sensors, 19, 460. https://doi.org/10.3390/s19030460

Amalathas, S., Mitrović, A., \& Ravan, R. (2012). Decision-Making Tutor: Providing On-the-Job Training for Oil Palm Plantation Managers. Research and Practice in Technology Enhanced Learning, 7, 131-152.

Andersen, M. H. (2011). The World Is My School: Welcome to the Era of Personalized Learning. The Futurist, 45, 1-6.

Anderson, J. (1996). ACT: A Simple Theory of Complex Cognition. American Psychologist, 51, 355-365. https://doi.org/10.1037/0003-066X.51.4.355

Anderson, J., Corbett, A., Koedinger, K., \& Pelletier, R. (1995). Cognitive Tutors: Lesson Learned. Journal of the Learning Sciences, 4, 167-207. https://doi.org/10.1207/s15327809j1s0402 2

Ayop, M., Chaellappan, K., \& Ali, M. A. (2001). Intelligent Tutoring Tool for Digital Logic Design Course (ITDiL). Proceedings of IEEE Region 10 International Conference on Electrical and Electronic Technology, Singapore, 19-22 August 2001, 899-902.

Barbhuiya, R. K., Mustafa, K., \& Jabin, S. (2011). Design Specifications for a Generic Intelligent Tutoring System. Int'l Conf. e-Learning, e-Bus., EIS, and e-Gov, 399-404.

Beal, C., Arroyo, I., Cohen, P., \& Woolf, B. (2010). Evaluation of Animal Watch: An Intelligent Tutoring System for Arithmetic and Fractions. Journal of Interactive Online Learning, 9, 64-77.

Briggs, S. (29 March 2014). Intelligent Tutoring Systems-Can They Work for You? https://www.opencolleges.edu.au 
Brusilovsky, P., Eklund, J., \& Schwarz, E. (1998). Web-Based Education for All: A Tool for Developing Adaptive Courseware. Computer Networks and ISDN Systems, 30, 291-300. https://doi.org/10.1016/S0169-7552(98)00082-8

Butz, C., Hua, S., \& Maguire, R. B. (2004). Bits: A Bayesian Intelligent Tutoring System for Computer Programming. Proceedings of 9th Western Canadian Conference on Computing Education (WCCCE-2004), Okanagan University College Kelowna, BC ,Canada, 6-7 May 2004, 179-186.

Callear, D. (1999). Intelligent Tutoring Environments as Teacher Substitutes: Use and Feasibility. Educational Technology, 39, 6-8.

Casas, I., Imbrogno, J., Ochoa, S., \& Ogan, A. (2014). Cultural Factors in the Implementation and Use of an Intelligent Tutoring System in Latin America. World Conference on E-Learning in Corporate, Government, Healthcare, and Higher Education, 1, 323-331.

Cohen, P., Beal, C., \& Adams, N. (2008). The Design, Deployment and Evaluation of the Animal Watch Intelligent Tutoring System. Proceeding of the 2008 Conference on ECAI.

Dabae, L., Yeol Huh1, H., Chun, Y. L., \& Charles, M. (2018). Technology Functions for Personalized Learning in Learner-Centered Schools. Educational Technology Research and Development, 66, 1269-1302. https://doi.org/10.1007/s11423-018-9615-9

Dašić, P., Dašić, J., Crvenković, B., \& Šerifi, V. (2016). A Review of Intelligent Tutoring Systems in E-Learning. Annals of the University of Oradea, 15, 85-90.

Frasson, C., \& Aimeur, E. (1998). Designing a Multi-Strategic Intelligent Tutoring System for Training in Industry. Computers in Industry, 37, 153-167.

https://doi.org/10.1016/S0166-3615(98)00091-8

Ghali, M. A., Ayyad, A. A., Naser, S. A., \& Laban, M. A. (2018). An Intelligent Tutoring System for Teaching English Grammar. International Journal of Academic Engineering Research (IJAER), 1-6.

Grandbastien, M. (1999). Teaching Expertise Is at the Core of ITS Research. International Journal of Artificial Intelligence in Education, 10, 335-339.

Ignacio, C., Patricia, F., Marcia, B., \& Amy, O. (2015). Culture-Oriented Factors in the Implementation of Intelligent Tutoring Systems in Chile. AIED 2015 Workshop Proceedings, 1, 21-30.

Koedinger, K. R., Anderson, J. R., Hadley, W. H., \& Mark, M. A. (1997). Intelligent Tutoring Goes to School in the Big City. International Journal of Artificial Intelligence in Education, 8, 30-43.

Lepper, M., \& Woolverton, M. (2002). The Wisdom of Practice: Lessons Learned from the Study of Highly Effective Tutors. In J. Aronson (Ed.), Improving Academic Achievement: Impact of Psychological Factors on Education (pp. 135-158). Cambridge, MA: Academic Press. https://doi.org/10.1016/B978-012064455-1/50010-5

Lynch, M. (17 May 2018). The Benefits and Limitations of Machine Learning in Education.

https://www.thetechedvocate.org/the-benefits-and-limitations-of-machine-learning-ineducation/

Merrill, D., Reiser, B., Ranney, M., \& Trafton, J. (1992). Effective Tutoring Techniques: A Comparison of Human Tutors and Intelligent Tutoring Systems. Journal of the Learning Sciences, 2, 277-305. https://doi.org/10.1207/s15327809jls0203_ 2

Miliband, D. (2006). Choice and Voice in Personalised Learning. In Personalising Education (pp. 21-30). OECD. https://doi.org/10.1787/9789264036604-2-en

Mitrović, A. (2002). NORMIT: A Web-Enabled Tutor for Database Normalization. Pro- 
ceedings of International Conference on Computers in Education (ICCE-2002), Auckland, 3-6 December 2002, 1276-1280. https://doi.org/10.1109/CIE.2002.1186210

Mitrović, A. (2003). An Intelligent SQL Tutor on the Web. International Journal of Artificial Intelligence in Education, 13, 173-197.

Mitrović, A., Mayo, M., Suraweera, P., \& Martin, B. (2004). Constraint-Based Tutors: A Success Story. In Lecture Notes in Computer Science (pp. 337-387).

Nkambou, R. (2010). Modeling the Domain: An Introduction to the Expert Module. In R. Nkambou, J. Bourdeau, \& R. Mizoguchi (Eds.), Advances in Intelligent Tutoring Systems (pp. 15-32). Berlin, Heidelberg: Springer. https://doi.org/10.1007/978-3-642-14363-2 2

Nkambou, R., Frasson, C., \& Gauthier, G. (1998). A New Approach to ITS-Curriculum and Course Authoring: The Authoring Environment. Computers \& Education, 31, 105-130. https://doi.org/10.1016/S0360-1315(98)00022-0

Nwana, H. S. (1990). Intelligent Tutoring Systems: An Overview. Artificial Intelligence Review, 4, 251-277. https://doi.org/10.1007/BF00168958

Nye, B. D. (2014). Intelligent Tutoring Systems by and for the Developing World: A Review of Trends and Approaches for Educational Technology in a Global Context. International Journal of Artificial Intelligence in Education, 25, 177-203. https://doi.org/10.1007/s40593-014-0028-6

Paviotti, G., Rossi, P. G., \& Zarka, D. (2012). Intelligent Tutoring Systems: An Overview. Pensa Multimedia, 1-176.

Phobun, P., \& Vicheanpanya, J. (2010). Adaptive Intelligent Tutoring Systems for E-Learning Systems. Procedia-Social and Behavioral Sciences, 2, 4064-4069. https://doi.org/10.1016/j.sbspro.2010.03.641

Rus, V., Lintean, M. C., \& Azevedo, R. (2010). Computational Aspects of The Intelligent Tutoring System MetaTutor. Proceedings of the Twenty-Third International Florida Artificial Intelligence Research Society Conference, Daytona Beach, FL, 19-21 May 2010.

Salgueiro, F., Costa, G., Cataldi, Z., Lage, F., \& Garcia, R. (2005). Redefinition of Basic Modules of an Intelligent Tutoring System: The Tutor Module Workshop ITS's on the WWW. 8th World Conference of the AIED Society, Kobe, Japan, 18-22 August 1997, $18-22$.

Self, J. A. (1999). The Distinctive Characteristics of Intelligent Tutoring Systems Research: ITSs Care, Precisely. International Journal of Artificial Intelligence in Educations, 10, 350-364.

Shure, V. J., \& Psotka, J. (1995). Intelligent Tutoring Systems: Past, Present, and Future. In D. Jonassen (Ed.), Handbook of Research for Educational Communications and Technology (pp. 570-600). New York: Macmillan.

Shute, V. J., \& Psotka, J. (1996). Intelligent Tutoring Systems: Past, Present, and Future. In D. Jonassen (Ed.), Handbook of Research on Educational Communications and Technology (pp. 570-600). New York: Macmillan.

Smith, S., \& Blandford, A. (2003). ML Tutor: An Application of Machine Learning Algorithms for an Adaptive Web-Based Information System. International Journal of Artificial Intelligence in Education, 13, 235-261.

Soffar, H. (3 May 2019). Artificial Intelligence in Education, AI Tutors Features, Advantages \& Disadvantages. https://www.online-sciences.com

Sykes, E., \& Franek, F. (2004). A Prototype for an Intelligent Tutoring System for Students Learning to Program in Java ${ }^{\mathrm{Tm}}$. Advanced Technology for Learning, 1, 402-317. 
Vanlehn, K. (2006). The Behavior of Tutoring Systems. International Journal of Artificial Intelligence in Education, 227-265.

VanLehn, K., Lynch, C., Schulze, K., \& Shapiro, J. (2005). The Andes Physics Tutoring System: Five Years of Evaluations. Proceedings of the 12th International Conference on Artificial Intelligence in Education, Amsterdam, 18-22 July 2005, 678-685.

Vassileva, J. (1989). Dynamic Course Generation on the WWW. Proceedings of the workshop ITS's on the WWW 8th World Conference of the AIED Society, Kobe, Japan, 18-22 August 1997, 18-22.

Vassileva, J., \& Deters, R. (1998). Dynamic Courseware Generation on the WWW. British Journal of Educational Technology, 29, 5-14. https://doi.org/10.1111/1467-8535.00041

Warendorf, K., \& Tan, C. (1997). ADIS-An Animated Data Structure Intelligent Tutoring System or Putting an Interactive Tutor on the WWW. Proceedings of 8th World Conference on Artificial Intelligence in Education (AI-ED'97), Kobe, Japan, 18-22 August 1997, 54-60.

Weber, G., \& Brusilovsky, P. (2001). ELM-ART: An Adaptive Versatile System for Web-Based Instruction. International Journal of Artificial Intelligence in Education, 12, 351-354.

Weber, G., \& Mollenberg, A. (1999). ELM-PE: A Student Model in an Intelligent Tutoring System. 11th IEEE International Conference on Tools with Artificial Intelligence (ICTAI'99), Chicago, 13-18.

Yamna, E., Mellouli, K., \& Wuillemin, P. (2010). A Multicriteria Bayesian Intelligent Tutoring System MBITS. Proceedings of 10th International Conference on Intelligent Systems Design and Applications (ISDA'10), Cairo, 29 November-1 December 2010, 714-719. https://doi.org/10.1109/ISDA.2010.5687181

Zhang, J. (2005). Intelligent Tutoring Systems: Research Status and Its Development in China. Proceedings of 12th International Conference on Natural Language Processing and Knowledge Engineering (NLP-KE'05), Wuhan, 30 October-1 November 2005, 683-689.

Zin, A., Aljunid, A., Shukur, Z., \& Nordin, M. (2000). A Knowledge-Based Automated Debugger in Learning System. Proceedings of 4th International Workshop on Automated Debugging, Universiti Kebangsaan Malaysia (UKM), Bangi, Selangor, 7 July 2000 . 